\title{
Tungsten-Induced Denaturation and Aggregation of Epoetin Alfa During Primary Packaging as a Cause of Immunogenicity
}

Andreas Seidl • Otmar Hainzl • Marleen Richter • Robert Fischer • Stephan Böhm • Britta Deutel • Martin Hartinger • Jörg Windisch $\bullet$ Nicole Casadevall $\bullet$ Gerard Michel London $•$ lain Macdougall

Received: 1 August 2011 / Accepted: 26 October 2011 / Published online: 18 November 2011

(C) The Author(s) 2011. This article is published with open access at Springerlink.com

\begin{abstract}
Purpose Following two cases of neutralizing antibodies to epoetin alfa in an investigational clinical study, a small number of individual syringes of two drug product batches were found to contain unusually high levels of aggregation at the end of the clinical trial.
\end{abstract}

Methods We undertook an extensive analytical approach to determine the root-cause of the increased aggregation in the affected batches.

Results Soluble tungsten was found in the syringes, most likely derived from the pins used to manufacture the syringes. Spiking of epoetin alfa with sodium polytungstate or an extract of tungsten pins used to manufacture the syringes induced the

\footnotetext{
A. Seidl $(\bowtie) \cdot O$. Hainzl $\cdot$ M. Richter $\cdot$ R. Fischer $\cdot$ M. Hartinger Sandoz Biopharmaceuticals, Hexal AG

Keltenring $1+3$

8204I Oberhaching, Germany

e-mail: andreas.seidl@sandoz.com

S. Böhm $\cdot$ B. Deutel $\cdot$ J. Windisch

Sandoz Biopharmaceuticals, Sandoz GmbH

Kundl, Austria

N. Casadevall

Hôpital Saint Antoine

Paris, France

G. M. London

Manhes Hospital

Fleury-Mérogis, France

I. Macdougall

King's College Hospital

London, UK

formation of aggregates, both dimers that appeared to be covalently linked by disulphide bonds as well as higher-order aggregates. Sodium polytungstate had also a strong denaturing effect on the protein.

Conclusions We propose tungsten-mediated unfolding and aggregation of epoetin alfa in pre-filled syringes as a potential root cause for increased immunogenicity. This finding may be more broadly applicable to this and other classes of therapeutic proteins.

KEY WORDS aggregation · epoetin · tungsten

\section{ABBREVIATIONS}

AF4

$C D$

CKD

C4-RP-HPLC

$K_{D}$

HP-SEC

HSA

ICP-OES

ITC

LO

MFI

PRCA

$R U$

SDS-PAGE

SPR

TFA asymmetric-flow field-flow fractionation

circular dichroism

chronic kidney disease

reversed-phase chromatography

equilibrium binding constant

high-performance size exclusion

chromatography

human serum albumin

inductively coupled plasma-optical

emission spectrometry

isothermal titration calorimetry

light obscuration

micro-flow imaging

pure red cell aplasia

resonance units

sodium dodecyl sulphate-polyacrylamide

gel electrophoresis

surface plasmon resonance

trifluoroacetic acid 


\section{INTRODUCTION}

Recombinant human erythropoietins have revolutionized the treatment of anemia associated with chronic kidney disease (CKD), and have been used for more than two decades. Pure red cell aplasia (PRCA) is a rare adverse effect of treatment with epoetins resulting from antibodies to the therapeutic product that cross-react with endogenous erythropoietin. PRCA is characterized by a rapidly progressive, severe anemia and by a complete absence of erythroid precursor cells in the bone marrow (1).

Before 1998, there were only three fully documented reports of anti-drug antibody-mediated PRCA following administration of epoetins (2). This situation changed in 1998, when manufacturing modifications, including the replacement of human serum albumin (HSA) as a stabilizer by the synthetic detergent polysorbate 80 and glycine, were introduced to epoetin alfa marketed outside the USA $\left(\right.$ Eprex $^{\circledR} /$ Erypo $^{\circledR}$; hereafter referred to as Eprex $\left.{ }^{\circledR}\right)$. Following this formulation change, the incidence of epoetinassociated PRCA increased dramatically $(2,3)$. By September 2002, the number of PRCA cases with documented neutralizing antibodies had risen to 112. In December 2002, the marketing authorization for subcutaneous administration of Eprex ${ }^{\circledR}$ was withdrawn. Root-cause investigations by the manufacturer of Eprex ${ }^{\circledR}$ led to the proposal that polysorbate 80 caused enhanced leaching of organic compounds from uncoated rubber stoppers in the drug syringes; it was hypothesized that these compounds acted as adjuvants, leading to the formation of neutralizing antibodies and the development of PRCA $(4,5)$. However, it is unclear whether an adjuvant alone can provoke breakdown of B-cell tolerance and induce the formation of antibodies against a self-protein, or if additional factors are involved (6-8).

More recently, two cases of neutralizing antibodies were reported during a pre-marketing clinical trial of a biosimilar epoetin (HX575) in subcutaneous administration in chronic renal failure subjects (9). In this paper, we present data showing that contamination by tungsten during the manufacture of the syringes used for primary packaging is the most likely cause of protein denaturation and aggregation, which may have led to the occurrence of two cases of neutralizing antibodies in the investigational clinical trial.

\section{MATERIALS AND METHODS}

\section{Size-Exclusion Chromatography (HP-SEC)}

Separation of epoetin monomer, dimer and higher-order aggregates under native conditions was performed on a BioSep ${ }^{\circledR}$ SEC S3000 column $(30 \times 0.78 \mathrm{~cm}, 5 \mu \mathrm{m})$ using an isocratic mobile phase containing $0.4 \mathrm{M} \mathrm{NaCl}, 8.1 \mathrm{mM}$ $\mathrm{Na}_{2} \mathrm{HPO}_{4} / 1.5 \mathrm{mM} \mathrm{KH}{ }_{2} \mathrm{PO}_{4}$ at $\mathrm{pH} 7.4$, with a flow rate of $0.4 \mathrm{ml} / \mathrm{min}$. For detection, a diode array detector was used with a detection wavelength of $206 \mathrm{~nm}$ (bandwith $2 \mathrm{~nm}$ ), and a reference wavelength of $245 \mathrm{~nm}$ (bandwith $2 \mathrm{~nm}$ ) to suppress the signal from polysorbate 80 .

\section{Reversed-Phase Chromatography (C4-RP-HPLC)}

Separation of the epoetin monomer and irreversible dimer was performed on a reversed-phase C4 column $(15 \times 0.21 \mathrm{~cm}$, $5 \mu \mathrm{m}, 300 \mathrm{~A}$ ) from Vydac using a gradient mobile phase of $0.08 \%$ trifluoroacetic acid (TFA) in water (mobile phase A) and $0.06 \%$ TFA in acetonitrile (mobile phase $\mathrm{B}$ ). The column was initially equilibrated with $5 \% \mathrm{~B}$ at a flow rate of $0.3 \mathrm{ml} /$ min. The separation was performed using a linear gradient of $5 \% \mathrm{~B}$ to $38 \% \mathrm{~B}$ for $5 \mathrm{~min}, 38 \% \mathrm{~B}$ to $50 \% \mathrm{~B}$ for $20 \mathrm{~min}$ and $50 \%$ B to $100 \%$ B for $5 \mathrm{~min}$, followed by isocratic elution for $5 \mathrm{~min}$ and flushing to the starting conditions $(5 \% \mathrm{~B})$. Detection was performed using a diode array detector with a detection wavelength of $206 \mathrm{~nm}$ (2) and a reference wavelength of $250 \mathrm{~nm}$ (2). The column temperature was set to $30^{\circ} \mathrm{C}$ and an injection volume of $100 \mu \mathrm{l}$ was chosen for sample concentrations between 16.8 and $84.0 \mu \mathrm{g} / \mathrm{ml}$.

\section{Tungsten Determination}

Protein solution $(2.000 \mathrm{~g})$ was mixed with $3.0 \mathrm{ml} \mathrm{HNO}_{3}$ $(65 \%)$ and $3.0 \mathrm{ml}$ deionised water. A microwave digestion was performed (MLS mPrep A T640, $T=210^{\circ} \mathrm{C}$ ). The solution was cooled to room temperature, transferred to a PE-vial and filled to $20 \mathrm{ml}$ with deionised water. Metals were determined by inductively coupled plasma-optical emission spectrometry (ICP-OES; Perkin Elmer OPTIMA 2000 DV). The limit of detection for chromium was $0.05 \mathrm{ppm}$, and for all other elements was $0.5 \mathrm{ppm}$.

\section{Tungsten Spiking and Pin Extract Studies: Sample Preparation}

Tungsten spiking experiments were performed with six tungsten species, all purchased from Sigma-Aldrich (Seelze, Germany): tungsten metal powder $(<10 \mu \mathrm{m})$, (Cat. 357421); tungsten (IV) oxide, (Cat 400505) and tungsten (VI) oxide (Cat 204781) (poorly soluble); sodium tungstate dihydrate (Cat 379751), ammonium tungstate (Cat 322385) and sodium polytungstate (Cat 71913) (highly soluble).

A solution of $336 \mu \mathrm{g} / \mathrm{ml}$ of epoetin alfa in formulation buffer (phosphate buffer, $\mathrm{pH}$ 7.0, containing the excipients sodium chloride and polysorbate 80) was spiked with each tungsten species to final tungsten concentrations of approximately $2 \mathrm{ppm}$ and $20 \mathrm{ppm}$. The amount of tungsten in each sample was confirmed using ICP-OES. 
Tungsten pin extract was prepared from 100 used pins, extracted for $2 \mathrm{~h}$ at room temperature in $20 \mathrm{ml}$ epoetin alfa formulation buffer placed in an ultrasonic bath. The solution was passed through a $0.2 \mu \mathrm{m}$ filter to remove big particles of tungsten oxides or tungsten metal. The tungsten level in the extract was approximately $200 \mathrm{ppm}$. The pin extract was added to a solution of $336 \mu \mathrm{g} / \mathrm{ml}$ of epoetin alfa in formulation buffer to final tungsten concentrations of approximately 2 and $20 \mathrm{ppm}$.

Samples were placed in clear type-I glass ampoules to exclude syringe-related variables. Ampoules were filled with $700 \mu \mathrm{l}$ of sample under inert gas (nitrogen), and stored at $2-8^{\circ} \mathrm{C}$ for 12 months or at $25^{\circ} \mathrm{C}$ for 6 months.

\section{Sodium Dodecyl Sulphate-Polyacrylamide Gel Electrophoresis (SDS-PAGE)}

SDS-PAGE was performed using NuPAGE ${ }^{\circledR}$ Novex $^{\circledR} 4$ $12 \%$ bis-Tris gels $(1.00 \mathrm{~mm} \times 10$ well $)$ and the $\mathrm{NuPAGE}^{\circledR}$ MES SDS running buffer (Invitrogen). The SeeBlue ${ }^{\circledR}$ pre-stained protein standard was used as a molecular weight marker. Samples were diluted with water to the appropriate concentration, mixed 1:1 with sample buffer and denatured for $5 \mathrm{~min}$ at $95^{\circ} \mathrm{C}$. For reduced samples, 2mercaptoethanol was added to the sample buffer. The denatured samples were centrifuged for $5 \mathrm{~min}$ and an appropriate volume pipetted into the gel pockets. The operating conditions were set according to the manufacturer's instructions $(22 \mathrm{~V}, 120 \mathrm{~mA} /$ gel at the start, $25 \mathrm{~W}$ : run time $55 \mathrm{~min})$. The gels were then stained with silver (silver staining kit, SERVA) according to the manufacturer's instructions.

\section{Circular Dichroism (CD)}

CD experiments were performed using a Chirascan plus instrument (Applied Photophysics Ltd, Leatherhead, UK) supplied with a thermostatted cell holder (QNW 250 ${ }^{\mathrm{TM}}$, Quantum Northwest Inc., Liberty Lake, WA, USA). FarUV CD experiments were run in quartz cuvettes of $0.5 \mathrm{~mm}$ path length (Starna Optiglass Ltd, Hainault, UK) in the wavelength range $195-250 \mathrm{~nm}$, at a spectral resolution of $0.5 \mathrm{~nm}$ and a time constant of $0.2 \mathrm{~s}$. CD experiments were run in epoetin alfa formulation buffer with variable amounts of tungsten added. Time-resolved measurements were performed at $208 \mathrm{~nm}$, with 100 point measurements at timed intervals of $40 \mathrm{~s}$ and a time constant of $1 \mathrm{~s}$.

\section{Surface Plasmon Resonance (SPR)}

SPR experiments were performed on a Biacore T100 instrument (GE Healthcare, Biacore, Freiburg, Germany). Epoetin alfa was coupled to the surface of a CM5 sensor chip using a standard amine coupling procedure as described by the manufacturer, yielding approximately 3,000 resonance units (RU). Measurements were performed at $25^{\circ} \mathrm{C}$ in epoetin alfa formulation buffer at a flow rate of $10 \mu \mathrm{l} / \mathrm{min}$. Increasing concentrations of sodium polytungstate $(0.67,1.68,3.35,6.7,10.1,13.4,16.8,33.5$ and $67 \mu \mathrm{M})$ were rinsed over the epoetin alfa-coupled chip surface for $600 \mathrm{~s}$. The apparent equilibrium constant $\left(\mathrm{K}_{D}\right)$ was calculated by plotting the steady-state binding signal versus applied concentration of sodium polytungstate using a least square algorithm based on the following equation: $\mathrm{RU}=\mathrm{RU}_{\max } \mathrm{c}\left(\mathrm{C}+K_{\mathrm{D}}\right)^{-1}$.

\section{Isothermal Titration Calorimetry (ITC)}

ITC experiments were conducted using an iTC200 instrument (MicroCal, GE Healthcare, Piscataway, NJ, USA) at $25^{\circ} \mathrm{C}$, set to deliver 40 injections $(5 \mu \mathrm{l})$ at $180 \mathrm{~s}$ intervals. In the titration experiments, $300 \mu \mathrm{M}$ sodium polytungstate in formulation buffer was injected from the syringe to $30 \mu \mathrm{M}$ epoetin, or to buffer in the measurement cell. Changes in the temperature of the solution $(\Delta \mu \mathrm{Cal})$ were buffer- and dilution-corrected and integrated. The integrated data were fit with a one-site binding model using the Origin-7 ${ }^{\mathrm{TM}}$ software provided from the manufacturer.

\section{RESULTS}

\section{Analysis of the Study Medication for Risk Factors for Immunogenicity}

In response to the occurrence of two cases of neutralizing antibodies during the pre-marketing clinical study with subcutaneous use of epoetin alfa, a comprehensive clinical and analytical investigation was implemented to determine the root cause of neutralizing antibodies. The analytical investigations included an in-depth risk assessment of the following quality attributes that may be linked to immunogenicity based on previous reports in the literature (4-6, 8, 10): dimers/aggregates/particles; protein denaturation; protein modification/degradation; leachates from the primary packaging; silicone oil; polysorbate micelles; host-cell proteins and other process-related impurities (Table I). Indepth analyses of retained and retrieved samples of those batches that were used for treatment of the two patients were performed and then compared with other batches from the clinical trial and reference batches; these comparisons revealed no differences for almost all parameters with the notable exception of aggregates, unfolded variants and inorganic (tungsten) variants (Table I). As aggregation is known to be highly relevant in the context of immunogenicity of biopharmaceuticals (11), the study medication was 
Table I Overview of Most Relevant Risk Factors for Immunogenicity Investigated and Evaluation of Results

\begin{tabular}{|c|c|c|c|c|c|}
\hline \multirow[t]{2}{*}{ Potential risk factor } & \multicolumn{3}{|c|}{ Suspect batches had higher levels than? } & \multirow{2}{*}{$\begin{array}{l}\text { Literature available to suggest } \\
\text { a role in immunogenicity }\end{array}$} & \multirow{2}{*}{$\begin{array}{l}\text { Involvement in } \\
\text { current root-cause }\end{array}$} \\
\hline & $\begin{array}{l}\text { Other batches } \\
\text { of study drug }\end{array}$ & $\begin{array}{l}\text { Other batches not } \\
\text { used as study drug }\end{array}$ & $\begin{array}{l}\text { Reference } \\
\text { product }\left(\text { Eprex }^{\circledR}\right)\end{array}$ & & \\
\hline \multicolumn{6}{|l|}{ Drug substance } \\
\hline Aggregation ${ }^{a, b}$ & No & No & $N / A$ & Yes $(10-12)$ & Highly unlikely \\
\hline Subvisible particles ${ }^{a}$ & No & No & $N / A$ & Yes $(13,14)$ & Highly unlikely \\
\hline Oxidation Met-54 & No & No & $N / A$ & No & Highly unlikely \\
\hline $\begin{array}{l}\text { Deamidation/aspartate } \\
\text { isomerization }^{\mathrm{a}}\end{array}$ & No & No & $N / A$ & Yes (17) & Highly unlikely \\
\hline Unfolded variants $^{\mathrm{a}}$ & No & No & $\mathrm{N} / \mathrm{A}$ & Yes (18) & Highly unlikely \\
\hline Host-cell proteins & No & No & $\mathrm{N} / \mathrm{A}$ & Yes (19) & Highly unlikely \\
\hline \multicolumn{6}{|l|}{ Drug product } \\
\hline Aggregation ${ }^{a, b}$ & Yes & Yes & No & Yes $(10-12)$ & Most likely \\
\hline $\begin{array}{l}\text { Unfolded variants }{ }^{\mathrm{a}} / \text { irreversible } \\
\text { dimers }\end{array}$ & Yes & Yes & Yes & Yes (। 8) & Most likely \\
\hline Subvisible particles ${ }^{a}$ & No & No & No & Yes $(13,14)$ & Unlikely \\
\hline Inorganic leachates ${ }^{d}$ & Yes (tungsten) & Yes (tungsten) & Yes (tungsten) & $\mathrm{No}^{\mathrm{d}}$ & Most likely \\
\hline Organic leachates $^{b}$ & No & No & No & Yes (8) & Highly unlikely \\
\hline Oxidation Met-54c & No & No & No & No & Highly unlikely \\
\hline Oxidation Trp-64 & No & No & No & No & Highly unlikely \\
\hline $\begin{array}{l}\text { Deamidation/aspartate } \\
\text { isomerization }^{\mathrm{a}}\end{array}$ & No & No & No & Yes $(17)$ & Highly unlikely \\
\hline Degradation $^{\mathrm{e}}$ & No & No & No & Yes $(23,24)$ & Highly unlikely \\
\hline Silicone oilf & No & No & No & Unclear (5, 25-27) & Highly unlikely \\
\hline Polysorbate 80 micelles $^{g}$ & No & No & No & No $(5,8,28)$ & Highly unlikely \\
\hline
\end{tabular}

${ }^{a}$ Generally known to be a risk factor for immunogenicity of proteins

${ }^{\mathrm{b}}$ Specific reports/experience available in the context of immunogenicity of epoetins

${ }^{\mathrm{c}}$ For other products, e.g. interferon alpha $2 \mathrm{~b}$, it has been shown that metal-induced oxidation can increase immunogenicity. However, the oxidation was not the direct immunogen but induced aggregation, which in turn increased immunogenicity $(15,16)$

$\mathrm{d}$ There are no reports that inorganic leachates may increase immunogenicity. However, data in the literature indicate that tungsten may induce aggregation (20-22), which in turn can result in immunogenicity

${ }^{\mathrm{e}}$ Disintegration of the primary structure as controlled by peptide mapping and capillary zone electrophoresis. Degradation could be fragmentation of the protein backbone as well as modification of amino acids

${ }^{\mathrm{f}}$ Silicone oil/gels may have adjuvant properties in animals but are not immunogenic per se. No case studies with biopharmaceutical products have been published. However, silicone oil may induce aggregation, which in turn can increase immunogenicity $(5,25-27)$

${ }^{\mathrm{g}}$ Incorporation of epoetin into polysorbate 80 micelles was suggested as a risk factor (28), but was subsequently considered to be unlikely $(5,8)$

screened for this parameter with a wide range of orthogonal analytical methods, including high-performance size exclusion chromatography (HP-SEC), analytical ultracentrifugation (AUC), asymmetric-flow field-flow fractionation (AF4), micro-flow imaging (MFI) and light obscuration (LO). The selected methods make use of different separation and detection principles to cover the complete size range of soluble and insoluble aggregates as well as particles (28). For most of the applied aggregation methods (with the exception of HP-SEC, see below), no relevant differences were observed between different batches of study medication and between study medication and reference batches. Furthermore, the shape and morphology of detected particles allowed the conclusion that detected particles were silicone oil droplets derived from the surface of siliconized syringes. In addition, a placebo batch showed similar levels of particles allowing the conclusion that the observed particles are non-proteinaceous. However, when drug product batches (pre-filled syringes) of the study medication were re-analyzed by routine HP-SEC for the presence of dimers and higher-order aggregates, a small number of individual syringes of two drug product batches (\#260108 and \#270108) were found to contain unusually high levels of aggregation after the trial was terminated (Table II and Fig. 1a). This observation was made when retained samples and retrieved samples from the supply chain and the different clinical centers were compared with reference batches. Each patient in the study received the drug at only 
Table II Screening of the Study Medication for the Presence of Dimers/Aggregates: Results of QC SEC-HPLC Method (Results Printed in Blue Indicate Batches which were Applied for Treatment of at Least One of the Patients with Neutralizing Antibodies; Results Printed in Red were Obtained with Study Medication Retrieved from the Clinical Centres of One of the Two Affected Patients)

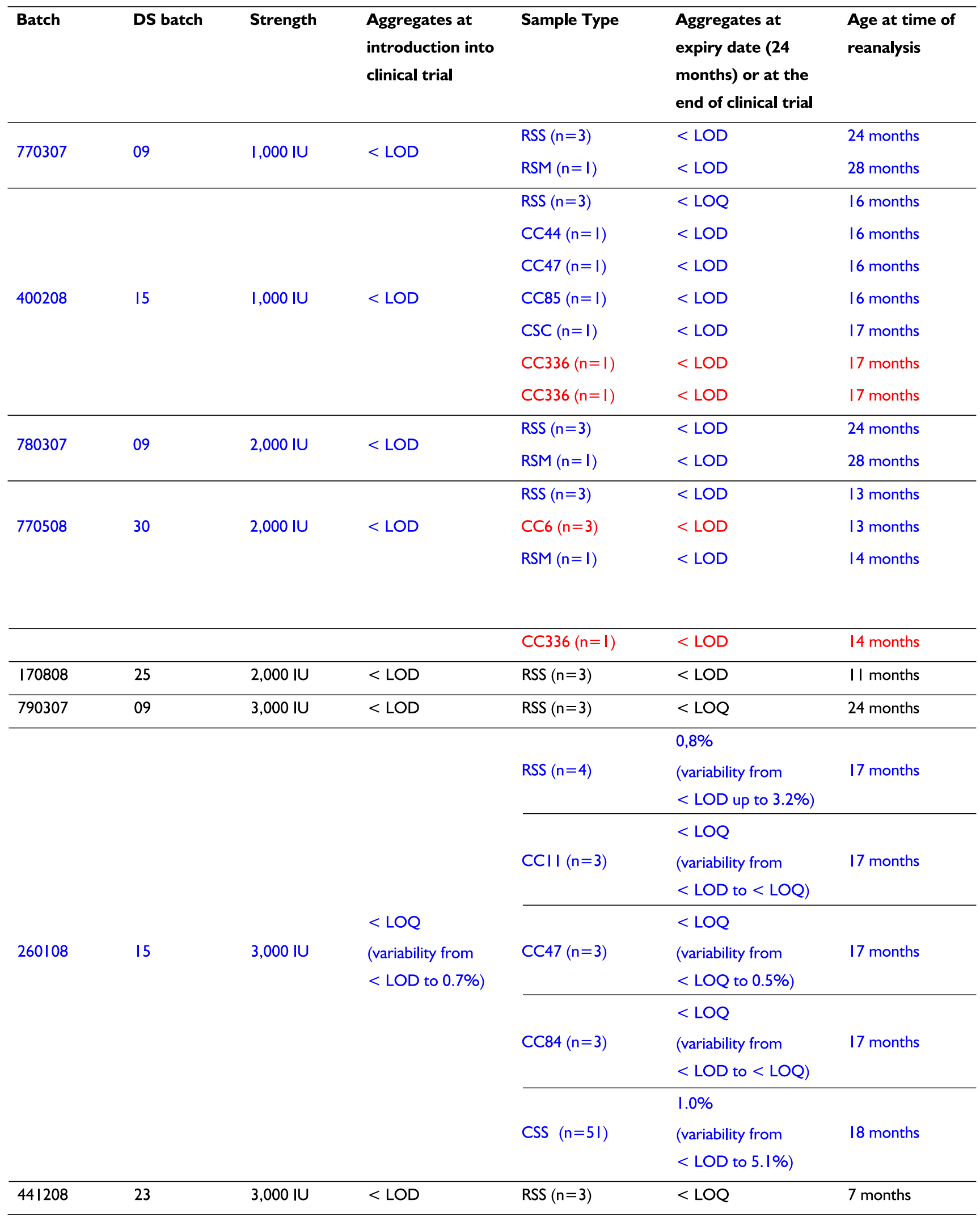


Table II (continued)

\begin{tabular}{|c|c|c|c|c|c|c|}
\hline Batch & DS batch & Strength & $\begin{array}{l}\text { Aggregates at } \\
\text { introduction into } \\
\text { clinical trial }\end{array}$ & Sample Type & $\begin{array}{l}\text { Aggregates at } \\
\text { expiry date ( } 24 \\
\text { months) or at the } \\
\text { end of clinical trial }\end{array}$ & $\begin{array}{l}\text { Age at time of } \\
\text { reanalysis }\end{array}$ \\
\hline 800307 & 09 & $4,000 \mathrm{IU}$ & $<$ LOD & $\operatorname{RSS}(n=3)$ & $<$ LOD & 24 months \\
\hline \multirow{6}{*}{270108} & \multirow{6}{*}{15} & \multirow{6}{*}{$4,000 \mathrm{IU}$} & \multirow{6}{*}{$<$ LOD } & $\operatorname{RSS}(n=3)$ & $\begin{array}{l}0.5 \% \\
\text { (variability from } \\
\text { <LOQ to } 0.8 \% \text { ) }\end{array}$ & 17 months \\
\hline & & & & CC6 $(n=1)$ & $<$ LOD & 17 months \\
\hline & & & & & $0.2 \%$ & \\
\hline & & & & $\operatorname{CSS}(n=5 \mid)$ & (variability from & 18 months \\
\hline & & & & & $<$ LOD to $1.5 \%)$ & \\
\hline & & & & CC336 $(n=1)$ & $<\mathrm{LOQ}$ & 18 months \\
\hline 150808 & 23 & $4,000 \mathrm{IU}$ & $<$ LOD & $\operatorname{RSS}(n=3)$ & $<\mathrm{LOQ}$ & II months \\
\hline 810307 & 09 & $5,000 \mathrm{IU}$ & $<$ LOD & $\operatorname{RSS}(n=3)$ & $<$ LOD & 24 months \\
\hline 280108 & 15 & $5,000 \mathrm{IU}$ & $<$ LOD & $\operatorname{RSS}(n=3)$ & $<$ LOQ & 18 months \\
\hline 160808 & 23 & $5,000 \mathrm{IU}$ & $<$ LOD & $\operatorname{RSS}(n=3)$ & $<$ LOD & II months \\
\hline 451208 & 23 & $5,000 \mathrm{IU}$ & $<$ LOD & RSS $(n=3)$ & $<$ LOQ & 7 months \\
\hline
\end{tabular}

LOD: $0.06 \%$ for 3,000-5,000 IU and 0.40\% for I,000 and 2,000 IU, LOQ: 0.3\% for 3,000-5,000 IU and I.8\% for I,000 and 2,000 IU

Blue-Batches applied as study medication to the affected patients having developed neutralizing antibodies

Red-Retrieved samples of the clinical centres of the affected patients

Black-Further epoetin alfa batches used in the clinical trial or reference batches

Sample type:

RSS: Retained Sample stored at clinical trial sponsor

RSM: Retained Sample stored at drug product manufacturing site

CSS: Clinical Sample stored at clinical trial sponsor (batch after blinding)

CSC: Clinical Sample from the supply chain

CCxx: Clinical Centre xx (retrieved sample from clinical centre xx)

a single clinical center, the affected two patients either at Clinical Center 6 or Clinical Center 336. However, study medication was retrieved wherever possible from all clinical centers and from the entire supply chain in order to investigate if transport, storage or handling in the different centers had an influence on the quality of the product. There were no hints that the product was shipped, stored or handled inappropriately or that handling and storage instructions were violated. Individual syringes of batch \#260108 contained aggregation levels ranging from below the limit of detection up to $5.1 \%$; syringes from batch \#270108 contained aggregation levels ranging from below the limit of detection up to $1.5 \%$ (Table II). On average, pre-filled syringe batch \#260108 contained higher levels of aggregation than batch \#270108, although both batches were filled from the same compounded solution containing material from the same drug-substance batch, and both were produced using the same batch of syringes. The two pre-filled syringe drug product batches differed only in their filling volumes $(300 \mu \mathrm{l}$ and $400 \mu \mathrm{l})$. These observations indicated that the primary packaging (syringes) may play a role in the aggregation of the active ingredient of these two batches. Also the observed syringe-to-syringe variability of the obtained aggregation values of these two batches substantiated the suspicion that the cause of aggregation is related to the primary packaging and not to the manufacturing process of drug substance or drug product. Reference batches used in the Eprex ${ }^{\circledR}$ arm of the clinical trial were also screened by HP-SEC, and 

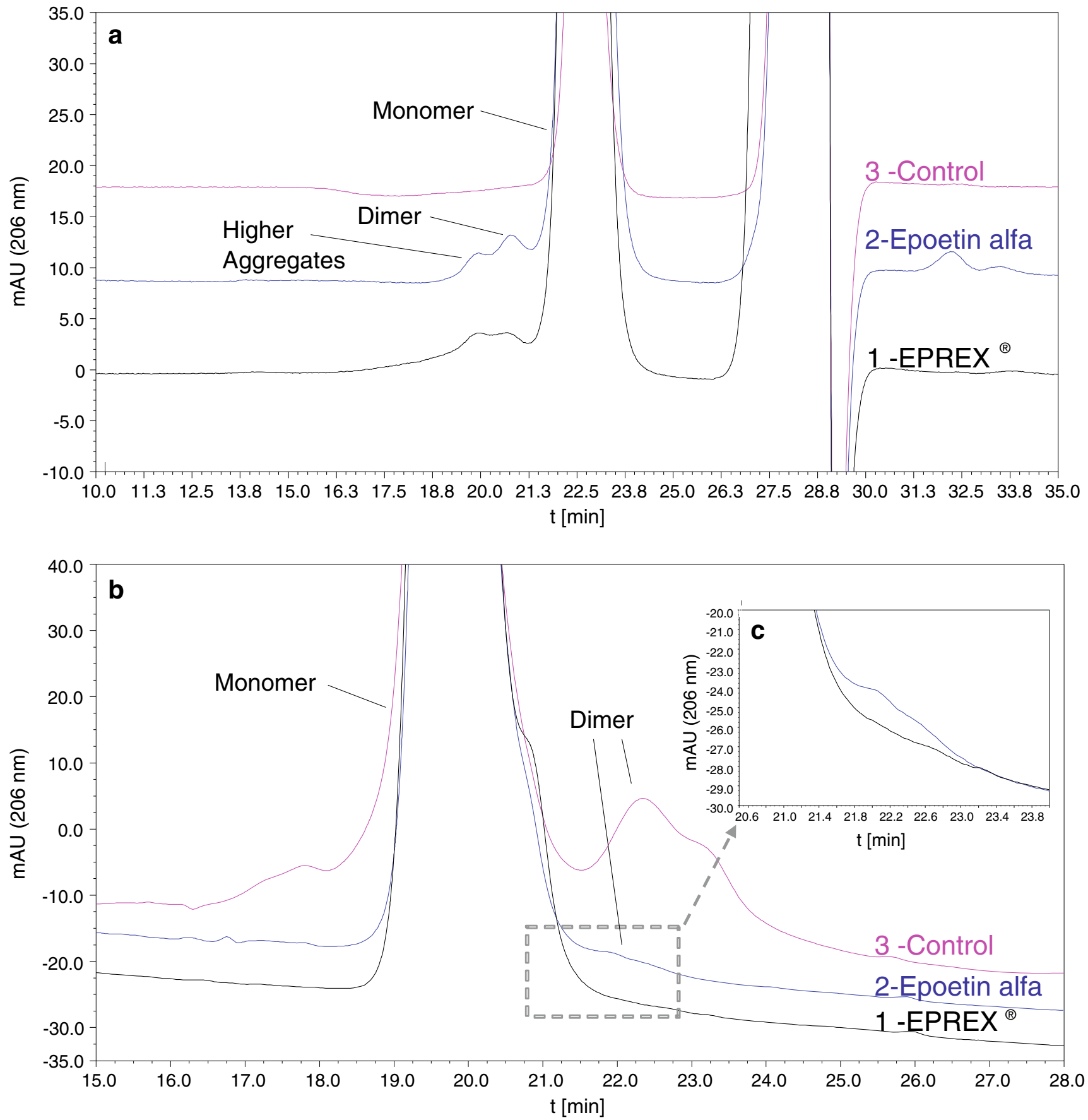

Fig. I Detection of dimers and aggregates in drug product batches of the study medication by HP-SEC and characterization of properties by C4-RPHPLC. (a) HP-SEC of the working standard (pink, negative control for dimers/aggregates), one syringe of epoetin alfa batch $260 \mathrm{I} 08$ (blue) and one syringe of Eprex ${ }^{\circledR}$ batch 8JSSZOI; (b) C4-RP-HPLC of a temperature-stressed sample (pink, positive control for dimers/aggregates), epoetin alfa drug product batch 260108 (blue) and one syringe of Eprex ${ }^{\circledR}$ batch 8JSSZOI; (c) Zoom of the area in which the more hydrophobic compound elutes with the retention time of irreversible dimers.

aggregates were found at levels comparable to or even higher than those found in the two suspect batches (Table III). The Eprex ${ }^{\circledR}$ batches were applied for the treatment of approximately $50 \%$ of the patient population of the clinical trial, however not for the treatment of the patients that developed neutralizing antibodies.

\section{Characterisation of Dimers and Aggregates}

In order to investigate the characteristics of the dimers/ aggregates observed in the two suspect pre-filled syringe drug product batches of epoetin alfa, samples of these batches were also analyzed by a C4-RP-HPLC method that 
Table III Results of the Determination of Dimers and Aggregates in the Study Medication of the Eprex ${ }^{\circledR}$ Arm of the Clinical Trial

\begin{tabular}{|c|c|c|c|c|}
\hline Batch & Strength & $\begin{array}{l}\text { Aggregates at implementation } \\
\text { into clinical trial }\end{array}$ & $\begin{array}{l}\text { Aggregates at expiry date } \\
\text { ( } 18 \text { months) or at the end of clinical trial }\end{array}$ & $\begin{array}{l}\text { Age at the end of } \\
\text { clinical trial }\end{array}$ \\
\hline 7ASSSOI & I,000 IU & $<\mathrm{LOD}$ & $<\mathrm{LOD}$ & 18 months \\
\hline 7ESSW02 & I,000 IU & $<\mathrm{LOD}$ & $<\mathrm{LOD}$ & 18 months \\
\hline 7JSSJ00 & I,000 IU & $<\mathrm{LOD}$ & $<\mathrm{LOD}$ & 18 months \\
\hline 7KSSH0O & I,000 IU & $<\mathrm{LOD}$ & $<$ LOD & 18 months \\
\hline 8ESSU00 & I,000 IU & $<\mathrm{LOD}$ & $<\mathrm{LOQ}$ & 14 months \\
\hline 7BSSG00 & 2,000 IU & $<\mathrm{LOQ}$ & $<\mathrm{LOD}$ & 18 months \\
\hline 7EST000 & 2,000 IU & $<\mathrm{LOD}$ & $<\mathrm{LOD}$ & 18 months \\
\hline 7GSSR00 & 2,000 IU & $<\mathrm{LOD}$ & $<\mathrm{LOD}$ & I 8 months \\
\hline 7JSS300 & 2,000 IU & $<\mathrm{LOD}$ & $<\mathrm{LOD}$ & 18 months \\
\hline 8BSSE00 & $2,000 \mathrm{IU}$ & $<\mathrm{LOD}$ & $<\mathrm{LOQ}$ & 17 months \\
\hline 8DSSB00 & $2,000 \mathrm{IU}$ & $<\mathrm{LOQ}$ & $<\mathrm{LOD}$ & I 5 months \\
\hline 7CSST00 & $3,000 \mathrm{IU}$ & $<\mathrm{LOD}$ & $1.7 \%(n=4$, variability from 1.3 to $1.9 \%)$ & 18 months \\
\hline 7FSSY02 & $3,000 \mathrm{IU}$ & $<L O D$ & $2.9 \%(n=4$ from 2.3 to $4.1 \%)$ & 18 months \\
\hline 7GSSU02 & $3,000 \mathrm{IU}$ & $<L O D$ & $0.6 \%(n=4$ variability from 0.3 to $1.4 \%)$ & 18 months \\
\hline 8ASSROI & $3,000 \mathrm{IU}$ & $<L O D$ & $1.3 \%(n=50$, variability from $0.2 \%$ to $5.3 \%)$ & 18 months \\
\hline 8DSSY00 & $3,000 \mathrm{IU}$ & I.3\% $(n=6$, variability from $<$ LOD to $3.2 \%)$ & $1.1 \%$ & I5 months \\
\hline 7CSSY00 & $4,000 \mathrm{IU}$ & $<L O D$ & $<\mathrm{LOD}$ & 18 months \\
\hline 7EST40I & $4,000 \mathrm{IU}$ & $<\mathrm{LOD}$ & $1.2 \%$ & 18 months \\
\hline 8BSSG0। & $4,000 \mathrm{IU}$ & $<L O D$ & $1.7 \%$ & 17 months \\
\hline 8ESSK02 & $4,000 \mathrm{IU}$ & $<\mathrm{LOD}$ & $1.0 \%$ & 14 months \\
\hline 7BSSQ00 & $5,000 \mathrm{IU}$ & $<\mathrm{LOD}$ & $<\mathrm{LOD}$ & 18 months \\
\hline 7EST802 & $5,000 \mathrm{IU}$ & $<\mathrm{LOD}$ & $<\mathrm{LOD}$ & 18 months \\
\hline 7KSSU00 & $5,000 \mathrm{IU}$ & $<\mathrm{LOD}$ & $1.2 \%$ & 18 months \\
\hline 8GST300 & $5,000 \mathrm{IU}$ & $0.9 \%$ & $0.6 \%$ & 12 months \\
\hline
\end{tabular}

LOD: $0.06 \%$ for 3,000-5,000 IU and 0.40\% for I,000 and 2,000 IU, LOQ: $0.3 \%$ for 3,000-5,000 IU and I.8\% for I,000 and 2,000 IU

allows the detection of folding variants with different hydrophobicity and/or irreversible dimers.

Samples of the study medication were also compared with a temperature-stressed sample that contained stable dimers (Fig. 1b). Using this method it was shown that samples of the suspect epoetin alfa batches contained a compound that eluted from the C4-RP-HPLC column with a retention time similar to that of the dimer fraction of the stressed control sample. Therefore, it was concluded that a small proportion of the total dimers was stable (or irreversible) and could not be dissociated under the denaturing conditions of the C4-RPHPLC (Fig. 1b). In contrast, no irreversible dimers or folding variants were detected in samples of Eprex ${ }^{\circledR}$ study medication by C4-RP-HPLC, although dimers/aggregates could be detected by HP-SEC (Fig. 1b, c).

\section{Assessments of Leachates from the Primary Packaging}

Syringes from suspect batches of the pre-marketing study medication with a lower filling volume contained higher levels of aggregation. This observation, in addition to the significant syringe-to-syringe variability in the levels of aggregation in these specific batches, suggested a role for the syringe material (primary packaging) in the aggregation of HX575. Therefore, the study medication was analysed for leachables migrated from the primary packaging into the formulation buffer.

No unexpected organic leachates from the syringes were detected in the study medication, including the two suspect batches of epoetin alfa, using three different HPLC methods. More specifically, those organic leachates described in the literature as involved in the increased incidence of PRCA with Eprex ${ }^{\circledR}(4,5)$ were not detected. Study medication was also screened for inorganic leachates, and metal ions were quantified using ICP-OES. Soluble tungsten was detected in drug product syringes of epoetin alfa batches \#260108 and \#270108 in which unusual high levels of aggregates were found (Table IV, approximately $1 \mathrm{ppm}$ on average; up to $4 \mathrm{ppm}$ in individual syringes). This led to a more extensive investigation of the impact of tungsten on aggregation of the glycoprotein. For all other 


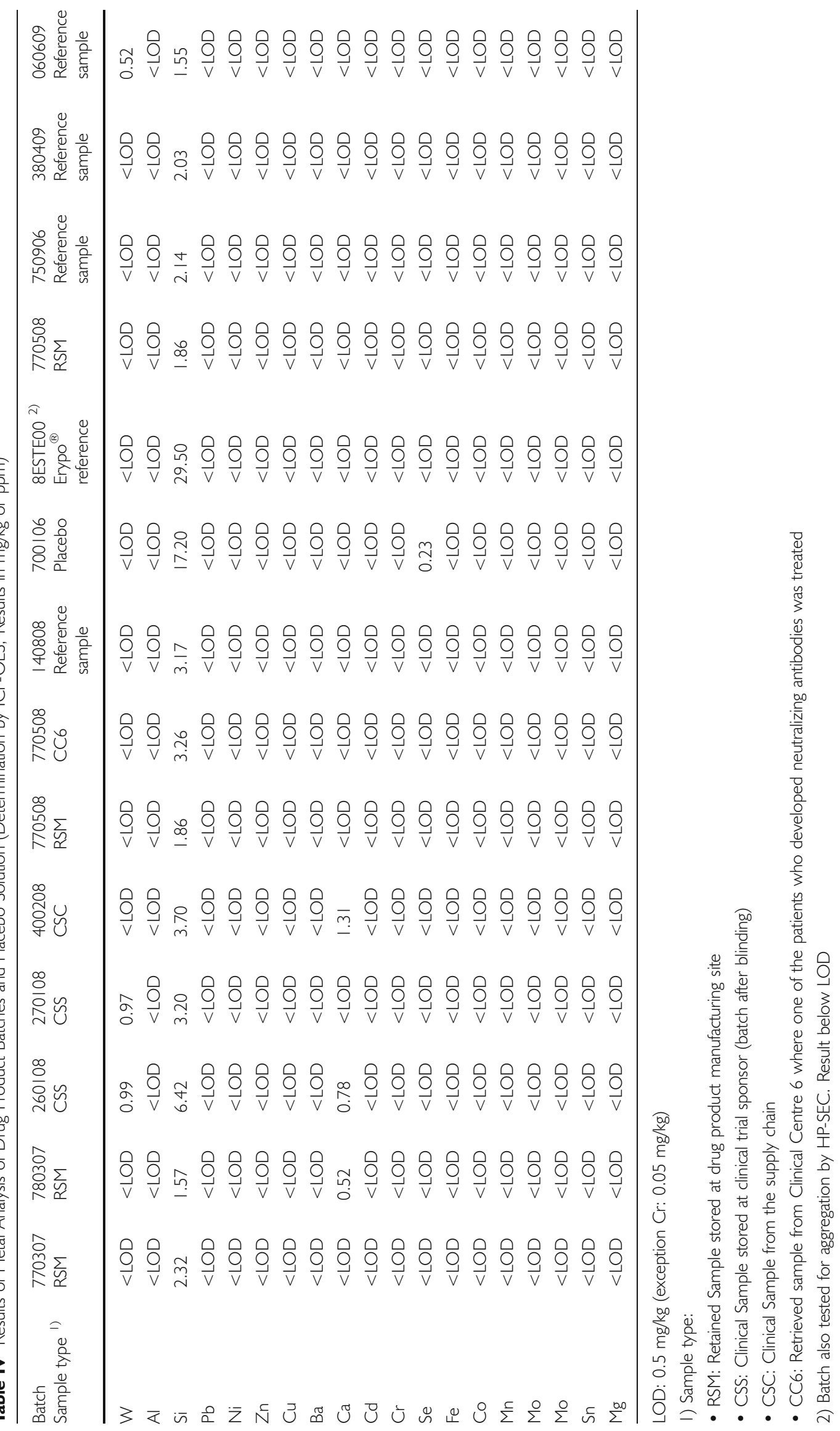


metal ions analyzed no differences were observed between the different batches of the study medication and the reference batches.

\section{Influence of Tungsten on Aggregation of Epoetin Alfa}

\section{Tungsten Spiking Studies}

A series of studies were performed in which epoetin alfa drug product solution $(336 \mu \mathrm{g} / \mathrm{ml})$ was spiked with a range of tungsten species at concentrations of approximately 2 and 20 ppm. The spiked samples were incubated with tungsten (IV) oxide, tungsten (VI) oxide; sodium tungstate dihydrate, sodium polytungstate, ammonium tungstate or tungsten metal powder at $5^{\circ} \mathrm{C}$ and $25^{\circ} \mathrm{C}$ for up to 9 months and then analyzed for the presence of dimers and higher-order aggregates. Samples spiked with $20 \mathrm{ppm}$ sodium polytungstate were prone to aggregation as dimers and higher molecular weight forms were detected by HP-SEG (Fig. 2a) and their content increased during storage at $5^{\circ} \mathrm{C}$ and $25^{\circ} \mathrm{C}$. Analysis by C4-RP-HPLC confirmed the presence of a compound with higher hydrophobicity, similar to the compound found in the samples of the epoetin alfa study medication (Fig. 2b).
Tungsten-spiked samples were also analyzed by SDSPAGE/silver staining under reducing and non-reducing conditions. Under non-reducing conditions (Fig. 2c), three bands were visible after silver staining that were interpreted as monomer, dimer and higher-molecular-weight aggregates. Under reducing conditions (Fig. 2d), only the monomer was visible after silver staining, indicating that the dimer and higher aggregates were linked by disulphide bonds.

\section{Tungsten Pin Extract Studies}

Spiking studies were also performed using tungsten species originating from tungsten pins used to manufacture the syringes in which the final product was provided for use. Epoetin alfa drug product solution $(336 \mu \mathrm{g} / \mathrm{ml})$ was spiked with pin extract to tungsten concentrations of approximately 2 and $20 \mathrm{ppm}$. The spiked samples were incubated at $5^{\circ} \mathrm{C}$ and $25^{\circ} \mathrm{C}$ for up to 6 months and then analyzed by HP-SEC for the presence of dimers and higher-order aggregates. No aggregation was detected in any spiked sample less than 6 months old, irrespective of the tungsten level or incubation temperature (Table V). However, small

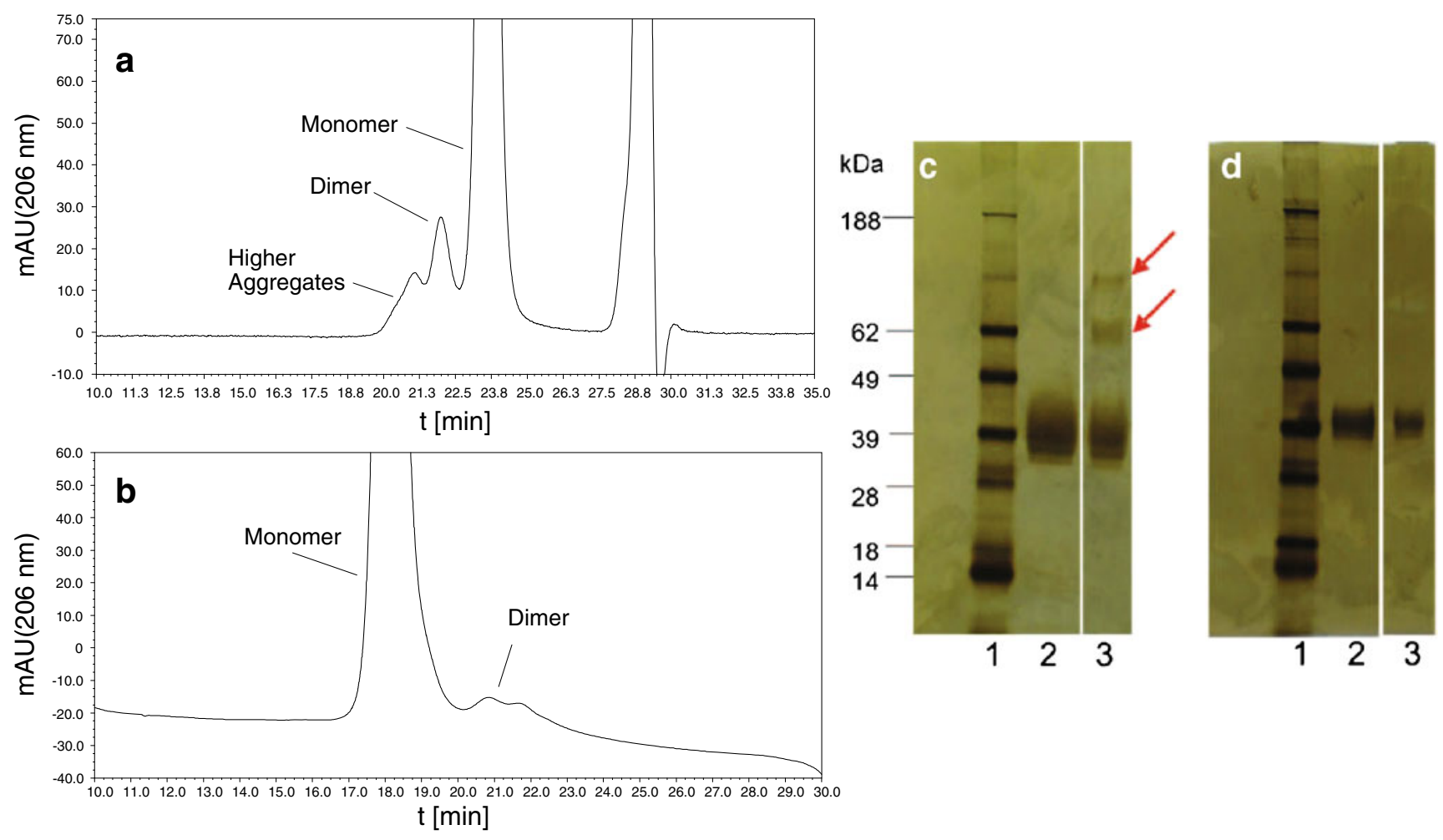

Fig. 2 Characterization of polytungstate-induced aggregation ( $20 \mathrm{ppm}$ sodium polytungstate incubated for 3 months at $25^{\circ} \mathrm{C}$ ) of epoetin alfa drug product with orthogonal analytical methods. (a) Detection of dimers and higher aggregates by HP-SEC; (b) Detection of the irreversible dimer fraction by C4-RPHPLC; (c) Detection of dimers and higher aggregates by SDS-PAGE under non-reducing conditions; (d) SDS-PAGE of the sample incubated with polytungstate under reducing conditions (dissociation of aggregates with 2-mercaptoethanol). SDS-PAGE: Bands which are assigned to dimers and aggregates are marked with red arrows. Lane I = molecular weight marker: lane 2 = epoetin alfa reference sample without polytungstate (negative control): lane 3 = epoetin alfa drug product $(336 \mu \mathrm{g} / \mathrm{ml})$ spiked with 20 ppm sodium polytungstate. 
Table V Aggregate Content of Epoetin Alfa Samples Spiked with Tungsten Pin Extract (0, 2 or 20 ppm) and Stored for 6 Months at $5^{\circ} \mathrm{C}$ or $25^{\circ} \mathrm{C}$ (Determination by HP-SEC)

\begin{tabular}{|c|c|c|c|c|}
\hline $\begin{array}{l}\text { Tungsten } \\
\text { concentration (ppm) }\end{array}$ & $\begin{array}{l}\text { Storage } \\
\text { temperature }\left({ }^{\circ} \mathrm{C}\right)\end{array}$ & $\begin{array}{l}\text { Epoetin alfa } \\
\text { monomer (relative area, \%) }\end{array}$ & $\begin{array}{l}\text { Epoetin alfa } \\
\text { dimer (relative area, \%) }\end{array}$ & $\begin{array}{l}\text { Epoetin alfa higher } \\
\text { aggregates (relative area, \%) }\end{array}$ \\
\hline 0 & 5 & 100.00 & ND & ND \\
\hline 2 & 5 & 99.95 & 0.05 & ND \\
\hline 20 & 5 & 99.33 & 0.42 & 0.25 \\
\hline 0 & 25 & 99.48 & 0.52 & ND \\
\hline 2 & 25 & 99.41 & 0.59 & ND \\
\hline 20 & 25 & 97.67 & 1.72 & 0.61 \\
\hline
\end{tabular}

amounts of aggregates were detected in spiked samples stored for at least 6 months; the level of aggregation was highest in samples spiked to 20 ppm tungsten and incubated at $25^{\circ} \mathrm{C}$.

\section{Tungsten Binding and Tungsten-Induced Unfolding of Epoetin Alfa}

The tungsten spiking experiments showed that sodium polytungstate has a strong potential to induce epoetin alfa aggregation. In order to assess the impact of the various tungsten species on the higher order structure of epoetin alfa, CD analysis of epoetin alfa-tungsten coincubated samples was performed. Samples were assayed either directly (in presence of the tungsten compound) or indirectly (after removal of insoluble tungsten via centrifugation). The various tungsten forms tested either caused partial depletion of epoetin alfa from solution (via adsorption), or altered the structural conformation of the epoetin alfa remaining in solution (data not shown). Again, sodium polytungstate had the strongest effect among the six tungsten compounds investigated, inducing significant structural changes in epoetin alfa. Therefore, the binding behaviour and influence of sodium polytungstate on the secondary structure of epoetin alfa was further assessed using SPR spectroscopy, ITC and CD spectroscopy. SPR spectroscopy demonstrated that sodium polytungstate binds rapidly to epoetin alfa and also dissociates rapidly, with an apparent $K_{\mathrm{D}}$ of $10.2 \pm 2.7 \mu \mathrm{M}$ (Fig. 3). The $K_{\mathrm{D}}$ determined by ITC $(10.3 \mu \mathrm{M})$ was consistent with the SPR value, and ITC results indicated a 1:1 binding stoichiometry between sodium polytungstate and epoetin alfa (data not shown).

The unfolding kinetics of $84 \mu \mathrm{g} / \mathrm{ml}(2.76 \mu \mathrm{M})$ epoetin alfa spiked with $20 \mathrm{ppm}(6.7 \mu \mathrm{M})$ sodium polytungstate at $20^{\circ} \mathrm{C}$ were monitored in real time, with a series of far-UV CD scans at intervals of approximately 2 min (Fig. 4). An effect of sodium polytungstate was detectable as little as 2 min after spiking of epoetin alfa, as indicated by the immediate onset of changes both in quantity (amplitude) and quality (signature) of the observed far-UV CD signal (Fig. 4a). Our observations indicate that the majority of the structural damage to epoetin alfa occurred approximately within the first $30 \mathrm{~min}$ of its interaction with sodium polytungstate (Fig. 4b). The observed unfolding of the protein during short-term incubation with polytungstate was largely reversible upon removal of the tungsten by dialysis. Furthermore, a direct effect of tungsten
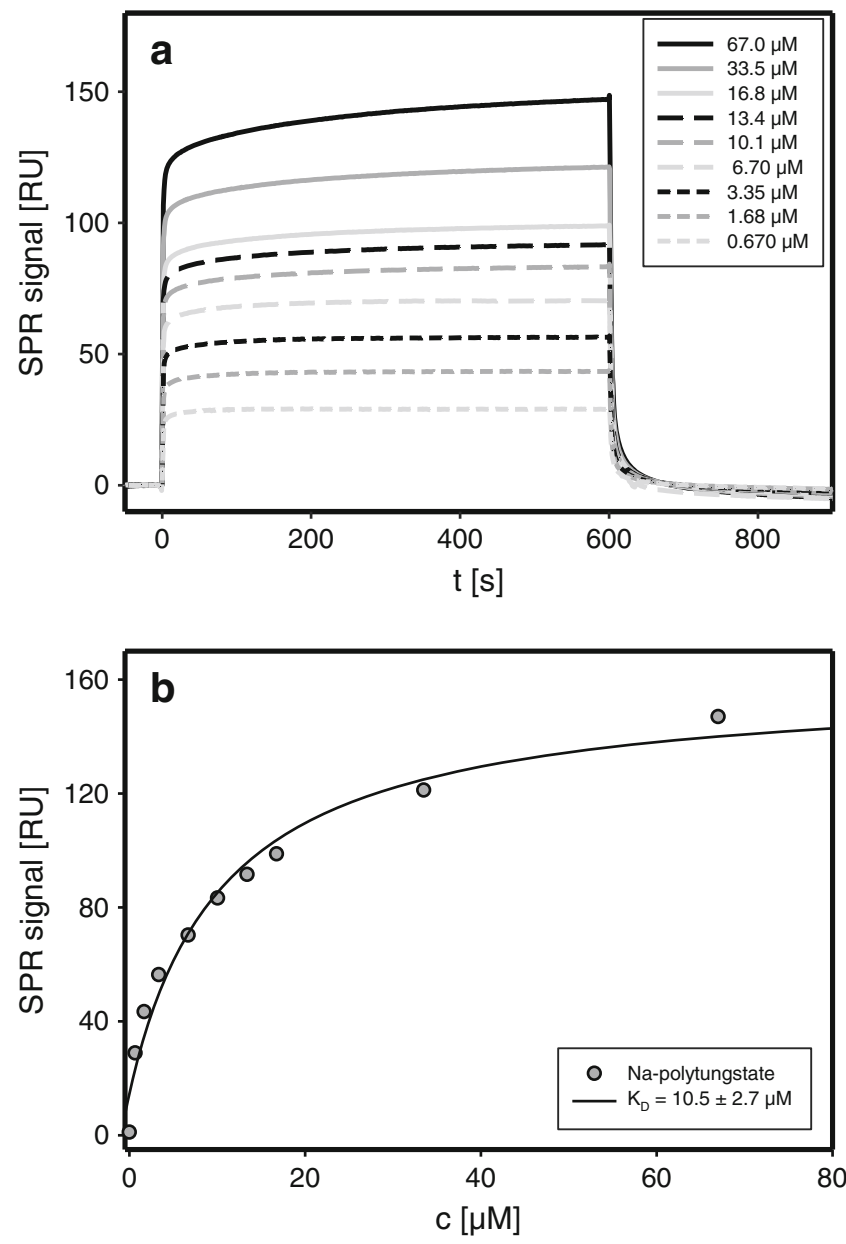

Fig. 3 SPR analysis of the interaction between immobilized epoetin alfa and sodium polytungstate. (a) Sodium polytungstate was injected at $25^{\circ} \mathrm{C}$ for $10 \mathrm{~min}$ at a flow rate of $10 \mu \mathrm{L} / \mathrm{min}$ (concentrations as indicated in figure inlay); (b) Plot of steady-state binding values (RU) versus sodium polytungstate concentration $(\mu \mathrm{M})$. 

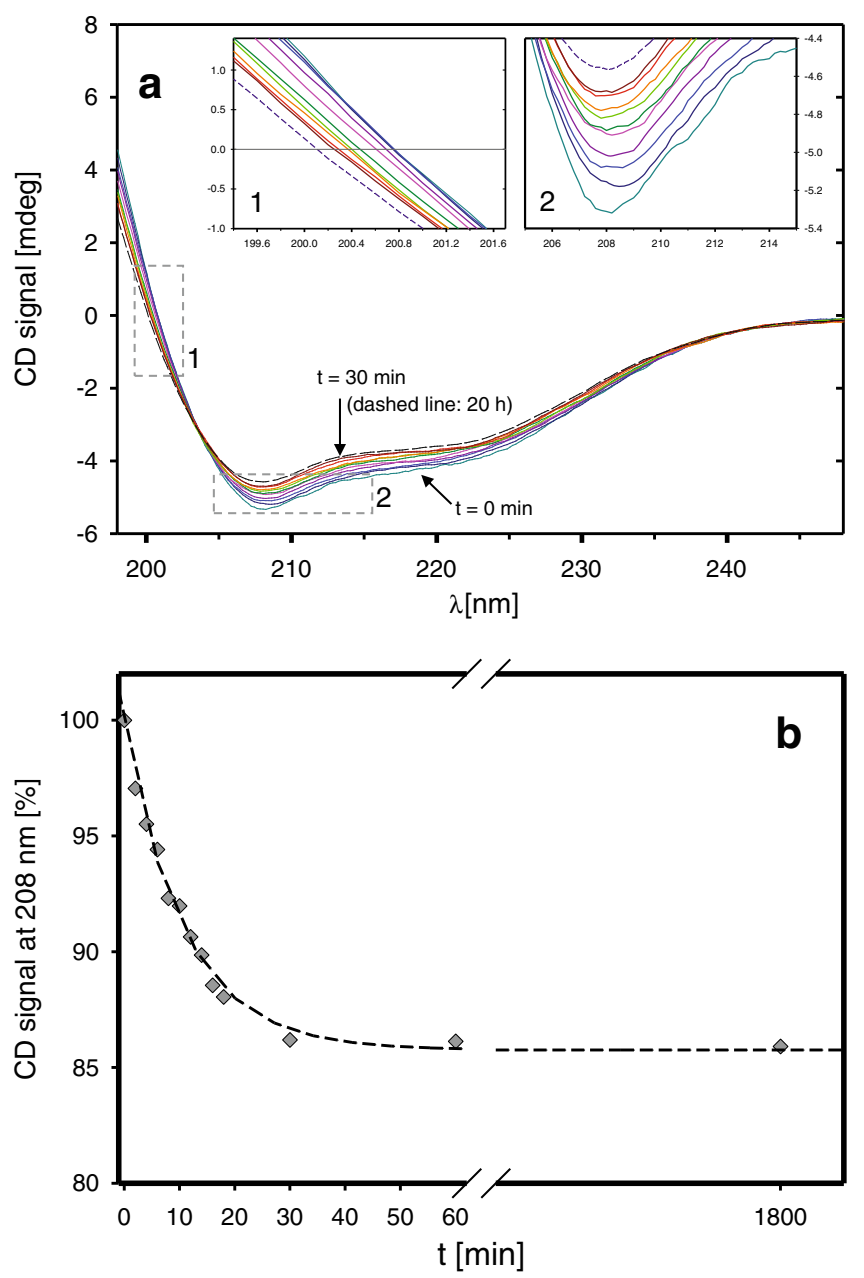

Fig. 4 Time-resolved epoetin alfa CD unfolding kinetics after addition of sodium polytungstate. (a) Overlay of far UV CD scans of epoetin alfa (84 $\mu \mathrm{g} / \mathrm{mL}$ ) before (cyan), shortly after (2-18 min, other colors), $30 \mathrm{~min}$ after (dark red) and $20 \mathrm{~h}$ after (dashed line) spiking with 20 ppm sodium polytungstate. Scans were collected every 2 min, starting from 2 min after the spiking event, until 18 min after spiking. Arrows indicate the start and endpoint scans. Inlays show enlarged views of 1 ) the region where the CD signal of epoetin alfa shifts from positive to negative $\left(\lambda_{0}\right)$ and 2$)$ the region of the negative CD signal maximum around $208 \mathrm{~nm}$; (b) Relative loss of CD signal at $208 \mathrm{~nm}$ after spiking with $20 \mathrm{ppm}$ sodium polytungstate, monitored over $30 \mathrm{~h}$.

from a tungsten pin extract was detected in real-time CD experiments (data not shown).

\section{DISCUSSION}

A battery of methods was applied to assess the quality attributes of drug-substance and drug product syringes in order to identify the potential root cause(s) of the two cases of neutralizing antibodies to erythropoietin in an investigational study. Retained and retrieved samples of batches applied to the two affected patients were compared with reference batches, other study drug batches and Eprex ${ }^{\circledR}$.
Unexpected results were obtained when the study medication was intensively evaluated for the presence of dimers and higher aggregates. Aggregation is recognised as an important factor in the breakdown of immune tolerance resulting in immunogenicity of therapeutic proteins $(6,8$, 11,30). Therefore, special emphasis was placed on this parameter. In addition to the HP-SEG method used routinely for quality control purposes, numerous orthogonal methods were employed; the methods used are based on different separation and detection principles to cover the complete size range of soluble and insoluble aggregates as well as subvisible and visible particles (13, 14, 29). For almost all methods applied, no relevant differences were detected in the batches used as study medication for the two affected patients, as compared with all other samples (other batches of the study medication and reference samples). Unexpectedly, an increased level of dimerisation/aggregation (in the aggregate size range covered by the routine quality control HP-SEC method) was detected in two drug product batches that were used to treat the affected patients. The level of dimers/aggregates detected in these suspect batches (up to $5 \%$ in individual syringes) had never previously been found for the drug product (pre-filled syringes), neither at release of any drug product batch nor in stability studies of batches until the end of their shelf-life.

Despite the fact that almost $50 \%$ of tested Eprex ${ }^{\circledR}$ batches used in the clinical trial contained levels of dimers and aggregates comparable to or higher than those in the two suspect batches of HX575, no patients treated with Eprex $^{\circledR}$ in the clinical study developed neutralizing antibodies. It is possible that this is purely a matter of chance, although an alternative explanation might be that specific characteristics of aggregates rather than the absolute level are important for the breakdown of immune tolerance. We therefore sought to characterize the nature of the protein dimers/aggregates in the suspect batches of the study medication, using newly established analytical techniques. These techniques indicated that the aggregated samples contained a species with higher hydrophobicity, which could be related to different folding or to a dimer fraction that could not be dissociated in the presence of organic solvents. Further tests showed that a proportion of these irreversible dimers could be dissociated only in the presence of reducing agents, indicating that they are covalently linked by disulphide bonds. These hydrophobic species could not be detected in samples of the Eprex ${ }^{\circledR}$ medication used in this study.

The two suspect batches of epoetin alfa differed only in their filling volumes, and the batch with the lower filling volume contained a higher level of aggregates. This finding, along with the observed variability in the level of aggregates from syringe to syringe, indicated the involvement of additional factors related to the syringes used as primary 
packaging. Several recent reports have implicated tungsten as a causative factor in the aggregation of pharmaceutical protein products (20-22). The tungsten most likely originates from tungsten pins used to form the barrels of the glass syringes in which the final product is provided for use (22). Our investigations detected tungsten in drug product extracts of the two suspect epoetin alfa clinical batches. We subsequently showed that sodium polytungstate, as well as an extract of the tungsten pins used to manufacture the syringes, induced dimerization/aggregation of epoetin alfa clinical product. These aggregates were similar to those detected in the two suspect batches of the study medication from the clinical trial, in that a proportion of the dimers could not be dissociated by organic solvents and were most likely covalently linked via disulphide bonds. We also demonstrated that sodium polytungstate can bind rapidly and reversibly to epoetin alfa and has a strong denaturing effect on the secondary structure of epoetin alfa clinical product, inducing rapid unfolding of the glycoprotein.

In addition to the aggregated species detected in the study medication, it is also possible that unfolded protein molecules might directly induce an immune response, by revealing novel epitopes that induce the formation of antibodies capable of cross-reacting with endogenous erythropoietin. This is more likely to occur after subcutaneous administration than after intravenous administration. Dilution of unfolded/aggregated protein and tungsten is likely to occur much less rapidly after subcutaneous administration due to restrictions in space, and therefore diffusion and movement of the administered solution, imposed by the subcutaneous extracellular matrix and cells. By contrast, dilution of unfolded/aggregated protein and any tungsten present (and therefore renaturation of the protein) will likely occur very rapidly after intravenous administration due to the large volume of blood and associated admixture.

The aggregation found in the suspect batches of the study medication is clearly linked to the drug product manufacturing process of producing pre-filled syringes, since dimers and aggregates were not detected in drugsubstance samples. In contrast to this, literature reports have indicated the presence of dimers/aggregates not only in Eprex ${ }^{\circledR}$ drug product but also in the drug substance at levels of approximately 1\% (31,32), suggesting dimers/ aggregates in Eprex ${ }^{\circledR}$ may be derived also from other steps in the overall manufacturing process than just the drug product manufacturing. The potential differences in origin and cause of unfolding and/or aggregation may explain the different structural characteristics of the dimers/aggregates detected in the study medication and the used Eprex ${ }^{\circledR}$ batches, and consequently the different immunogenic potential in this clinical trial. On the other hand, PRCA continues to occur at a very low incidence with the clinical use of Eprex ${ }^{\circledR}$ and other epoetins (3,33-35), despite the introduction of coated rubber stoppers which should have removed the previously hypothesized root cause of the PRCA outbreak associated with Eprex ${ }^{\circledR}$ between 1998 and $2002(4,5)$. Therefore, further investigation may be warranted of the role of unfolding and formation of irreversible dimers/aggregates as a root cause in the development of neutralising antibodies with epoetins. This suggestion is further supported by a recent report implicating aggregation as the root cause of PRCA cases following inappropriate transport and storage of Eprex ${ }^{\circledR}$ (12).

Considering recent reports on process changes implemented by a manufacturer of ready-to-fill syringes leading to higher residual tungsten levels in the syringes (22), and together with previous reports of tungsten-induced aggregation of pharmaceutical proteins (20-22), our findings highlight the importance of improving the manufacturing process for syringes to reduce the tungsten content to consistently low levels. The manufacturer of these clinical supplies has converted all syringes to low-tungsten components to prevent further excursions of tungsten and formation of these identified aggregates in future.

The results of the investigations could explain the root cause of the occurrence of two cases of neutralizing antibodies in an investigational clinical trial, and adds tungsten-induced unfolding to the list of previously described root causes for PRCA, among which are leachates from the primary packaging acting as adjuvants and heatinduced aggregation $(4,5,12)$. Our finding may also be more broadly applicable to this and other classes of therapeutic proteins and may contribute to a better understanding of immunogenicity of biopharmaceuticals.

\section{CONCLUSIONS}

We propose tungsten-mediated unfolding and aggregation of epoetin alfa in pre-filled syringes as a potential root cause for increased immunogenicity. This finding may be more broadly applicable to this and other classes of therapeutic proteins.

\section{ACKNOWLEDGMENTS \& DISCLOSURES}

We would like to thank Huub Schellekens, Utrecht University, for valuable scientific input and review of the manuscript and Mark McCamish, Sandoz Biopharmaceuticals, for review of the manuscript. Pin extracts were prepared by BD, Pont-deClaix, France, metal ion quantification was performed by CBA GmbH Kirkel-Limbach, Germany, and ITC by Alexander Bepperling/Technical University of Munich.

Andreas Seidl, Otmar Hainzl, Marleen Richter, Robert Fischer, Stephan Böhm, Britta Deutel, Martin Hartinger and Jörg Windisch are employed by Sandoz or affiliates. 
Nicole Casadevall and Iain Macdougall received fundings from AMGEN, Roche, Sandoz and Affymax.

Open Access This article is distributed under the terms of the Creative Commons Attribution Noncommercial License which permits any noncommercial use, distribution, and reproduction in any medium, provided the original author $(\mathrm{s})$ and source are credited.

\section{REFERENCES}

1. Macdougall IC. Antibody-mediated pure red cell aplasia (PRCA): epidemiology, immunogenicity and risks. Nephrol Dial Transplant. 2005;20 Suppl 4:iv9-iv15.

2. Casadevall N. Antibodies against rHuEPO: native and recombinant. Nephrol Dial Transplant. 2002;17 Suppl 5:42-7.

3. Bennett CL, Luminari S, Nissenson AR, Tallman MS, Klinge SA, McWilliams N, et al. Pure red-cell aplasia and epoetin therapy. N Engl J Med. 2004;351:1403-8.

4. Boven K, Stryker S, Knight J, Thomas A, van Regenmortel M, Kemeny DM, et al. The increased incidence of pure red cell aplasia with an Eprex formulation in uncoated rubber stopper syringes. Kidney Int. 2005;67:2346-53.

5. Boven K, Knight J, Bader F, Rosser J, Eckardt KU, Casadevall N. Epoetin-associated pure red cell aplasia in patients with chronic kidney disease: solving the mystery. Nephrol Dial Transplant. 2005;20 Suppl 3:iii33-40.

6. Schellekens H, Jiskoot W. Eprex-associated pure red cell aplasia and leachates. Nat Biotechnol. 2006;24:613-4.

7. Sharma B, Ryan MH, Boven K. Reactions to Eprex's adverse reactions. Nat Biotechnol. 2006;24:1199-200.

8. Schellekens H, Jiskoot W. Erythropoietin-associated PRCA: still an unsolved mystery. J Immunotoxicol. 2006;3:123-30.

9. Haag-Weber M, Eckardt KU, Hörl WH, Roger SD, Vetter A, Roth K. Safety, immunogenicity and efficacy of subcutaneous biosimilar epoetin alfa (HX575) in non-dialysis patients with renal anaemia: a multi-centre, randomised, double-blind study. Clin Nephrol. 2011 [accepted for publication]

10. Schellekens H. Factors influencing the immunogenicity of therapeutic proteins. Nephrol Dial Transplant. 2005;20 Suppl 6:vi3-9.

11. Rosenberg AS. Effect of protein aggregates: an immunologic perspective. AAPS J. 2006;8:E501-7.

12. Fotiou F, Aravind S, Wang PP, Nerapusee O. Impact of illegal trade on the quality of epoetin alfa in Thailand. Clin Ther. 2009;31:336-46.

13. Carpenter J, Cherney B, Lubinecki A, Ma S, Marszal E, Mire-Sluis $\mathrm{A}$, et al. Meeting report on protein particles and immunogenicity of therapeutic proteins: filling in the gap in risk evaluation and mitigation. Biologicals. 2010;38:602-11.

14. Carpenter JF, Randolph TW, Jiskoot W, Crommelin DJ, Middaugh CR, Winter G, et al. Overlooking subvisible particles in therapeutic protein products: gaps that may compromise product quality. J Pharm Sci. 2009;98:1201-5.

15. Hermeling S, Aranha L, Damen JMA, Slijper M, Schellekens H, Crommelin DJA, et al. Structural characterization and immunogenicity in wild-type and immune tolerant mice of degraded recombinant human interferon alpha2b. Pharm Res. 2005;22:1997-2006.

16. Hermeling S, Schellekens H, Maas C, Gebbink MF, Crommelin DJ, Jiskoot W. Antibody response to aggregated human interferon alpha2b in wild-type and transgenic immune tolerant mice depends on type and level of aggregation. J Pharm Sci. 2006;95:1084-96.

17. Mamula MJ, Gee RJ, Ellott JI, Sette A, Southwood S, Jones PJ, et al. Isoaspartyl post-translational modification triggers autoimmune responses to self-proteins. J Biol Chem. 1999;274:22321-7.

18. Maas C, Hermeling S, Bouma B, Jiskoot W, Gebbink MF. A role for protein misfolding in immunogenicity of biopharmaceuticals. J Biol Chem. 2007;282:2229-36.

19. Sharma B. Immunogenicity of therapeutic proteins. Part 3: impact of manufacturing changes. Biotechnol Adv. 2007;25:32531.

20. Bee JS, Nelson SA, Freund E, Carpenter JF, Randolph TW. Precipitation of a monoclonal antibody by soluble tungsten. J Pharm Sci. 2009;98:3290-301.

21. Jiang Y, Nashed-Samuel Y, Li C, Liu W, Pollastrini J, Mallard D, et al. Tungsten-induced protein aggregation: solution behavior. J Pharm Sci. 2009;98:4695-710.

22. Liu W, Swift R, Torraca G, Nashed-Samuel Y, Wen ZQ Jiang Y, et al. Root cause analysis of tungsten-induced protein aggregation in pre-filled syringes. PDA J Pharm Sci Tech. 2010;64:11-9.

23. Koren E, Zuckerman LA, Mire-Sluis AR. Immune responses to therapeutic proteins in humans-clinical significance, assessment and prediction. Curr Pharm Biotechnol. 2002;3:349-60.

24. Josic D, Buchacher A, Kannicht C, Lim YP, Löster K, Pock K, et al. Degradation products of factor VIII which can lead to increased immunogenicity. Vox Sang. 1999;77:90-9.

25. Naim JO, Lanzafame RJ, van Oss CJ. The adjuvant effect of silicone-gel on antibody formation in rats. Immunol Invest. 1993;22:151-61.

26. Naim JO, Ippolito KML, Lanzafame RJ. The effect of molecular weight and gel preparation on humoral adjuvancy of silicone oils and silicone gels. Immunol Invest. 1995;24:537-47.

27. Jones LS, Kaufmann A, Middaugh CR. Silicone oil induced aggregation of proteins. J Pharm Sci. 2005;94:918-27.

28. Hermeling S, Schellekens H, Crommelin DJ, Jiskoot W. Micelleassociated protein in epoetin formulations: a risk factor for immunogenicity? Pharm Res. 2003;20:1903-7.

29. Engelsman J, Garidel P, Smulders S, Koll H, Smith B, Bassarab $\mathrm{S}$, et al. Strategies for the assessment of protein aggregates in pharmaceutical biotech product development. Pharm Res. 2011;28:920-33.

30. Patten PA, Schellekens H. The immunogenicity of biopharmaceuticals. Lessons learned and consequences for protein drug development. Dev Biol. 2003;112:81-97.

31. Villalobos AP, Gunturi SR, Heavner GA. Interaction of polysorbate 80 with erythropoietin: a case study in protein-surfactant interactions. Pharm Res. 2005;22:1186-94.

32. Heavner GA, Arakawa T, Philo JS, Callman MA, Labrenz S. Protein isolated from biopharmaceutical formulations cannot be used for comparative studies: follow-up to a case study using epoetin alfa from Epogen and Eprex. J Pharm Sci. 2007;96:321425.

33. Kruger A, Schroer W, Rohrs F, Vescio G. PRCA in a patient treated with epoetin beta. Nephrol Dial Transplant. 2003;18:1033-4.

34. Howman R, Kulkarni H. Antibody-mediated acquired pure red cell aplasia (PRCA) after treatment with darbepoetin. Nephrol Dial Transplant. 2007;22:1462-4.

35. Jacob A, Sandhu K, Nicholas J, Jones H, Odum J, Rylance P, et al. Antibody-mediated pure red cell aplasia in a dialysis patient receiving darbepoetin alfa as the sole erythropoietic agent. Nephrol Dial Transplant. 2006;21:2963-5. 